\title{
Perencanaan Instalasi Pengolahan Air Limbah Mal X Kota Bandung
}

\author{
Gita Ayu Rahmawati ${ }^{1}$, Eka Wardhani ${ }^{2}$, Lina Apriyanti ${ }^{3}$ \\ 1,2,3 Jurusan Teknik Lingkungan, Fakultas Teknik Sipil dan Perencanaan, Itenas \\ J1.PHH. Mustapha 23, Bandung \\ Koresponden email: gitayurahma96@gmail.com
}

Diterima: 27 Juni 2019

Disetujui: 12 Juli 2019

\begin{abstract}
Absctract
Waste Water Treatment Plant (WWTP) in the shopping center is planned to cater for its constantly changing concept. The centre was to initially provide electronic services, however, it is currently providing food and beverage services. The changes will affect the amount of wastewater and the characteristics produced. Wastewater discharge is calculated from $80 \%$ of the $83.73 \mathrm{~m}^{3}$ of clean water needed per day. The concentration of the wastewater characteristics obtained for parameters BOD, COD, TSS, oil and fat were $182.67 \mathrm{mg} / \mathrm{l}$, $328.50 \mathrm{mg} / 1,255.92 \mathrm{mg} / 1,47.93 \mathrm{mg} / 1$ respectively. The selection of the processing alternatives is based on the descriptive method which uses a series of selected alternative unit screens, grease traps, equalization tanks, activated sludge, settling tanks and chlorination. The dimensions of the processing unit are calculated based on the selected alternatives. And the land requirements needed to build a WWTP at X Mall amounts to $80 \mathrm{~m}^{2}$.

Keywords: waste water treatment, characteristic, activated sludge, food and beverage, mall.
\end{abstract}

\begin{abstract}
Abstrak
Instalasi Pengolahan Air Limbah (IPAL) Mal X direncanakan karena terjadi perubahan konsep mal. Konsep awal merupakan mal penyedia jasa elektronik berubah menjadi mal penyedia jasa makanan dan minuman. Perubahan konsep mal akan mempengaruhi jumlah dan karakteristik air limbah yang dihasilkan. Debit air limbah dihitung dari $80 \%$ kebutuhan air bersih mal sebesar $83,73 \mathrm{~m}^{3} /$ hari. Konsentrasi dari karakteristik air limbah yang diperoleh untuk parameter BOD, COD, TSS, minyak dan lemak masing-masing sebesar 182,67 $\mathrm{mg} / 1 ; 328,50 \mathrm{mg} / 1 ; 255,92 \mathrm{mg} / \mathrm{l} ; 47,93 \mathrm{mg} / \mathrm{l}$. Pemilihan alternatif pengolahan air limbah menggunakan metode deskriptif dengan rangkaian unit alternatif terpilih yaitu saringan, perangkap minyak, bak ekualisasi, lumpur aktif, bak pengendap dan bak klorinasi. Dimensi unit pengolahan dihitung berdasarkan alternatif yang terpilih. Kebutuhan lahan yang diperlukan untuk membangun IPAL di Mal X sebesar $80 \mathrm{~m}^{2}$.

Kata kunci: pengolahan air limbah, karakteristik, lumpur aktif, makanan dan minuman, mal.
\end{abstract}

\section{Pendahuluan}

Pusat perbelanjaan atau biasa disebut mal selalu menjadi daya tarik masyarakat untuk berkunjung. Pengunjung biasanya tidak hanya menghabiskan waktu di mal untuk berbelanja namun juga untuk makan dan minum. Sebuah mal menyediakan lahan khusus untuk tempat makan dan minum disebut food court. Mal X yang berada di Kota Bandung mengalami perubahan kepemilikan. Kepemilikan baru melakukan renovasi dan mengubah konsep. Konsep awal berupa mal yang menyediakan jasa elektronik diubah menjadi mal yang khusus menyediakan jasa makanan dan minuman juga sebagai pusat kegiatan untuk komunitas kreatif Kota Bandung (Anonim, 2017)

Mal X menyediakan jenis makanan dan minuman yang beragam mulai dari dalam dan luar negeri dengan jumlah 304 tenan. Fasilitas pendukung bagi komunitas kreatif yang disediakan Mal X yaitu seperti studio musik, studio foto dan panggung pertunjukan untuk menampilkan karya, menyalurkan ide dan kolaborasi antar komunitas kreatif. Komunitas kreatif yang sudah bergabung dengan Mal X sebanyak 500 komunitas (Anonim, 2017).

Fasilitas-fasilitas yang dimiliki Mal X diharapkan menjadi daya tarik masyarakat dan komunitaskomunitas Kota Bandung untuk berkunjung.

Perkiraan jumlah pengunjung saat hari kerja sebanyak 200 pengunjung dan akan meningkat apabila sudah memasuki hari libur. Pengunjung akan lebih banyak lagi apabila diselenggarakan acara besar mencapai \pm 7.000 pengunjung (Anonim, 2017).

Jumlah pengunjung tentunya akan mempengaruhi timbulan air limbah yang dihasilkan. Air limbah yang tidak diolah akan terakumulasi dan bersifat septik, penguraian dari bahan organik yang dikandungnya akan menyebabkan gangguan pada badan air penerima 


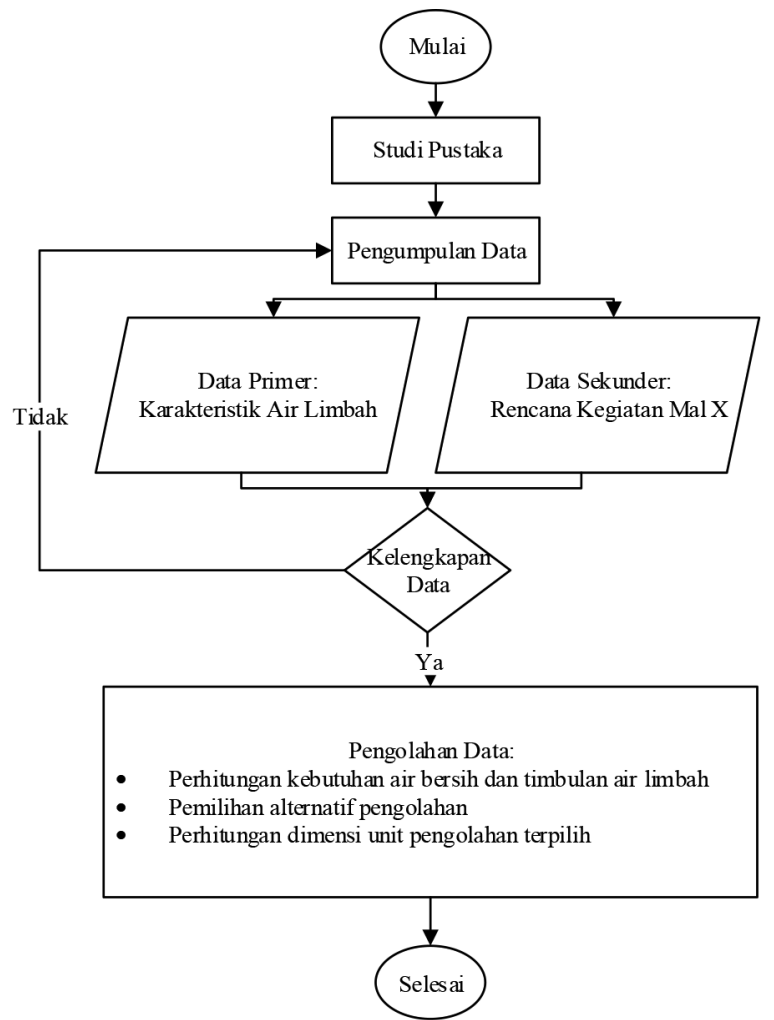

Gambar 1. Tahapan perencanaan IPAL Mal X

(Tchobanoglous dkk., 2004) .

Kondisi pengolahan air limbah di Mal X saat ini berupa tangki septik tanpa bidang resapan. Perubahan konsep mal menjadi food court akan meningkatkan jumlah dan perbedaan karakteristik air limbah sehingga diperlukan suatu unit pengolahan air limbah yang memadai. Tangki septik yang ada dikhawatirkan tidak akan mampu mengolah timbulan air limbah. Karakteristik air limbah yang berasal dari food court tidak jauh berbeda dengan karakteristik air limbah domestik dengan parameter kualitas air yaitu: Biological Oxygen Demand (BOD), Chemical Oxygen Demand (COD), Total Suspended Solid (TSS), minyak dan lemak. Air limbah yang berasal food court memiliki kandungan minyak lemak dan BOD yang lebih tinggi dibandingkan air limbah domestik. Kandungan minyak dan lemak di dalam air limbah akan mengganggu proses pengolahan dalam tangki septik. Sumber utama air limbah yang berasal dari dapur yaitu berasal dari pencucian peralatan makanan, air buangan sisa makanan dan sisa makanan seperti nasi, sayuran, minyak dan lemak (Zahra dan Purwanti, 2015) .

Telah banyak penelitian pengolahan air limbah khusus rumah makan seperti Hamid dan Razif (2014) yang meneliti Perbandingan perencanaan IPAL proses attach growth anaerobic filter dengan suspended growth anaerobic baffled reactor untuk pusat pertokoan di Kota Surabaya, Lukito (2017) yang melakukan perancangan ulang Instalasi Pengolahan Air Limbah (IPAL) pusat perbelanjaan " $X$ " Surabaya, serta Chen dan Lo (2006) yang meneliti tentang pengolahan air limbah restoran menggunakan sistem kombinasi lumpur aktif dan kontak aerasi.

Berdasarkan hal tersebut, direncanakan Instalasi Pengolahan Air Limbah (IPAL) untuk mengolah air limbah Mal X agar efluen yang dihasilkan tidak mencemari badan air penerima dan sesuai dengan baku mutu Peraturan Menteri Lingkungan Hidup dan Kehutanan (PERMEN LHK) No 68 Tahun 2016 tentang baku mutu air limbah domestik. Tujuan perencanaan ini adalah untuk menghitung timbulan air limbah yang dihasilkan dan merencanakan unit IPAL yang akan digunakan. Adapun manfaat dari perencanaan ini sebagai bahan pertimbangan dalam merencanakan IPAL di Mal X.

\section{Metodologi Penelitian}

Perencanaan IPAL di Mal X dibagi menjadi tiga tahapan yaitu studi pustaka, pengumpulan data baik primer dan sekunder dan pengolahan data. Pengolahan data terdiri dari tiga aspek utama yaitu perhitungan kebutuhan air bersih, timbulan air limbah, pemilihan alternatif IPAL dan perhitungan dimensi unit IPAL. Tahapan perencanaan dapat dilihat pada Gambar 1.

Tinjauan pustaka merupakan langkah awal yang diperlukan dalam perencanaan ini untuk menunjang tahapan perencanaan berikutnya. Pustaka yang ditinjau meliputi air limbah domestik dan rumah makan beserta sumbernya, karakteristik air limbah, baku mutu air limbah, pengolahan air limbah dan penelitian sejenis mengenai IPAL di pusat perbelanjaan. Pustaka diperoleh dari buku, jurnal dan regulasi terkait pengolahan limbah.

Pengumpulan data dalam perencanaan ini dikelompokan menjadi dua jenis data yaitu data primer dan data sekunder. Data primer yang dikumpulkan berupa karakteristik air limbah yang diperoleh dari hasil sampling dan pengukuran laboratorium. Pengambilan sampel air limbah dari pipa inlet bak kontrol sebelum masuk ke dalam tangki septik. Metode yang digunakan dalam pengambilan air sampel ini adalah grab sample. Menurut SNI 6989-59-

Tabel 1. Metode pengukuran karakteristik air limbah

\begin{tabular}{lc}
\hline \multicolumn{1}{c}{ Parameter } & Metode Pengukuran \\
\hline $\mathrm{pH}$ & SNI 06-6989.11-2004 \\
TSS & SNI 06-6989.3-2004 \\
BOD & SMEW 22nd ed:5210 B, 2012 \\
COD & SMEW 22nd ed:5220 D, 2012 \\
Amoniak & SNI 06-6989.30-2005 \\
Minyak dan lemak & SNI 6989.10:2011 \\
Total coliform & SMEW 22nd ed:9222 B, 2012 \\
\hline
\end{tabular}


Tabel 2. Standar kebutuhan air bersih Mal X

\begin{tabular}{lcc}
\hline \multicolumn{1}{c}{ Pemakaian Air } & Standar* & Satuan \\
\hline Karyawan & 50 & liter/orang $/$ hari \\
Tenan & 15 & liter $/ \mathrm{kursi}$ \\
Pengunjung & 5 & liter $/ \mathrm{m}^{2}$ \\
\hline
\end{tabular}

Keterangan: *SNI 03-0764-2005 tentang perencanaan sistem plumbing.

Setiap tenan akan diisi dengan sepuluh kursi (Anonim, 2017).

2008 tentang metoda pengambilan contoh air limbah grab sample merupakan metode di mana pengambilan sampel diambil sesaat pada lokasi tertentu .

Pengukuran karakteristik air limbah dilakukan di Laboratorium Pengendalian Kualitas Lingkungan Perusahaan Daerah Air Minum (LPKL PDAM) Tirtawening Kota Bandung. Parameter yang akan diukur meliputi $\mathrm{pH}, \mathrm{BOD}, \mathrm{COD}$, TSS, amoniak, minyak dan lemak, dan total coliform berdasarkan PERMEN LHK No 68 Tahun 2016 tentang baku mutu air limbah domestik tujuan pengukuran tersebut adalah untuk mengetahui konsentrasi pencemar air limbah di Mal X.

Metode yang digunakan untuk mengukur karakteristik air limbah ditampilkan pada Tabel 1.

Data sekunder yang dikumpulkan yaitu rencana kegiatan Mal X. Data tersebut diperlukan untuk mengetahui gambaran umum mal, fasilitas mal, jumlah karyawan, jumlah tenan, penggunaan lahan dan pengolahan air limbah yang sudah ada.

Pengolahan data dalam perencanaan IPAL meliputi: (a) perhitungan kebutuhan air bersih yang dihitung berdasarkan pemakaian air dari jumlah populasi dikalikan dengan standar pemakaian air. Jumlah populasi meliputi jumlah karyawan, jumlah tenan dan jumlah pengunjung yang dihitung berdasarkan luasan zona public. Standar pemakaian air bersih yang digunakan adalah SNI 03-70642005 tentang tata cara perencanaan sistem plambing. Setelah diperoleh kebutuhan air bersih selanjutnya menghitung timbulan air limbah. Peraturan Menteri Pekerjaan Umum dan Perumahan Rakyat (PERMEN PUPR) No 4 Tahun 2017 tentang perencanaan sistem penyaluran air limbah domestik, timbulan air limbah dihitung berdasarkan $60-80 \%$ pemakaian air bersih.

Standar kebutuhan air bersih Mal X disajikan pada Tabel 2 (b) rangkaian unit IPAL yang akan direncanakan dipilih dengan cara membandingkan kegiatan sejenis dan studi pustaka yang telah ditinjau. Penentuan alternatif terbaik/terpilih

Tabel 3. Kebutuhan air bersih Mal X

\begin{tabular}{lcc}
\hline \multicolumn{1}{c}{ Pemakaian Air } & $\sum$ & $\begin{array}{c}\text { Kebutuhan } \\
\left(\mathrm{m}^{3} / \mathrm{hari}\right)\end{array}$ \\
\hline Karyawan (orang) & 498 & 24,90 \\
Tenan (unit) & 304 & 45,60 \\
Pengunjung (orang) & 6.832 & 34,16 \\
\hline Total Kebutuhan Air & & 104,66 \\
\hline
\end{tabular}

Tabel 4. Hasil pengukuran air limbah Mal X

\begin{tabular}{lcccc}
\hline \multirow{2}{*}{ Parameter } & \multirow{2}{*}{ Satuan } & Baku & \multicolumn{2}{c}{ Hasil Pengukuran } \\
\cline { 3 - 5 } & & Mutu** & Hari Kerja & Hari Libur \\
\hline TSS & $\mathrm{mg} / \mathrm{l}$ & 30 & 24 & $35^{*}$ \\
$\mathrm{pH}$ & - & $6-9$ & 6 & 8 \\
$\mathrm{BOD}$ & $\mathrm{mg} / \mathrm{l}$ & 30 & 3 & 3 \\
$\mathrm{COD}$ & $\mathrm{mg} / \mathrm{l}$ & 100 & 8 & 8 \\
Amoniak & $\mathrm{mg} / \mathrm{l}$ & 10 & 0,2 & 0,1 \\
$\begin{array}{l}\text { Minyak } \\
\text { lemak }\end{array}$ & $\mathrm{mg} / 1$ & 5 & $<3$ & $<3$ \\
$\begin{array}{l}\text { Total } \\
\text { coliform }\end{array}$ & $\mathrm{mg} / 1$ & 3.000 & 440 & 410 \\
\hline Keterangan & & & & \\
\end{tabular}

Keterangan: *: Melebihi baku mutu

**: PERMEN LHK No. 68 Tahun 2016 tentang baku mutu air limbah domestik

menggunakan metode deskriptif di mana analisis suatu perencanaan dibandingkan dengan fakta kondisi saat ini (Sugiyono, 2017).

Pertimbangan pemilihan menggunakan dua faktor utama yaitu luas lahan yang diperlukan serta kemudahan pengoperasian unit pengolahan (c) perhitungan dimensi unit pengolahan air limbah hanya untuk alternatif yang terpilih. Pehitungan menggunakan kriteria perencanaan yang terdapat di berbagai literatur.

\section{Hasil dan Pembahasan \\ 3.1 Gambaran Umum}

Lokasi Mal X berada di Jalan Naripan No. 8389, Kelurahan Kebon Pisang, Kecamatan Sumur Bandung, Kota Bandung. Jumlah lantai di Mal X 12 lantai. Luas total seluruh lantai $37.111,60 \mathrm{~m}^{2}$ di mana luasan tersebut terbagi menjadi tiga zona yaitu: (a) zona retail 24.268,16 $\mathrm{m}^{2}$ (b) zona service $6.011,45 \mathrm{~m}^{2}$ dan (c) zona public $6.832,20 \mathrm{~m}^{2}$. Jam operasional mal 12 jam terbagi menjadi dua shift yaitu: shift I pukul 10.00-16.00 dan shift II pukul 16.00-22.00. Tenan makanan yang sudah beroperasi saat ini sebanyak 14 tenan dengan jenis makanan dan minuman yang di jual berasal dari dalam dan luar negeri.

Jumlah total tenan makanan yang akan beroperasi sebanyak 304 tenan. Jumlah tenaga kerja 498 orang terdiri dari staf mal dan tenan. Kebutuhan air bersih di Mal X disuplai oleh PDAM Tirtawening Kota

Tabel 5. Karakteristik air limbah penelitian sejenis

\begin{tabular}{|c|c|c|c|}
\hline \multirow{2}{*}{ Parameter } & \multicolumn{3}{|c|}{ Karakteristik Air Limbah (mg/l) } \\
\hline & Mal A $\mathrm{A}^{(1)}$ & $\mathrm{Mal} \mathrm{B}^{(2)}$ & Restoran $^{(3)}$ \\
\hline $\mathrm{BOD}$ & 134,50 & 248,50 & 165 \\
\hline COD & 232 & 397,50 & 356 \\
\hline TSS & 268 & 411,75 & 88 \\
\hline $\begin{array}{l}\text { Minyak dan } \\
\text { Lemak }\end{array}$ & 42 & 39,8 & 62 \\
\hline
\end{tabular}

Keterangan: 1) Lukito, 2017; 2) Hamid dan Razif, 2014; 3) Chen dan Lo, 2006 
Tabel 6. Perbandingan konsentrasi parameter air limbah sejenis dengan baku mutu

\begin{tabular}{lcccc}
\hline Parameter & Satuan & $\begin{array}{c}\text { Air } \\
\text { Limbah }\end{array}$ & $\begin{array}{c}\text { Baku } \\
\text { Mutu** }\end{array}$ & $\begin{array}{c}\text { Efisiensi } \\
(\%)\end{array}$ \\
\hline BOD & $\mathrm{mg} / 1$ & $182,67^{*}$ & 30 & 84 \\
COD & $\mathrm{mg} / 1$ & $328,50^{*}$ & 100 & 70 \\
TSS & $\mathrm{mg} / 1$ & $255,92^{*}$ & 30 & 88 \\
$\begin{array}{l}\text { Minyak dan } \\
\text { lemak }\end{array}$ & $\mathrm{mg} / 1$ & $47,93^{*}$ & 5 & 90 \\
\hline
\end{tabular}

Keterangan: *Melebihi baku mutu

** PERMEN LHK No. 68 Tahun 2016 tentang baku mutu air limbah domestik

Bandung sebanyak 95\% dan 5\% sisanya dari air tanah. Pengolahan air limbah saat ini menggunakan tangki septik tanpa bidang resapan yang sudah terbenam di dalam tanah. Lokasi IPAL Mal X akan dibangun di basement. Mal X menyediakan fasilitasfasilitas untuk mendukung komunitas kreatif dalam mengembangkan bakatnya. Komunitas kreatif yang sudah bergabung sebanyak 500 komunitas. Fasilitas yang disediakan antara lain panggung pertunjukan, studio foto dan studio musik (Anonim, 2017).

\subsection{Perhitungan Timbulan Air Limbah}

Perhitungan debit air limbah merupakan salah satu hal penting dalam perencaaan IPAL. Timbulan air limbah yang akan diolah di Mal X diperoleh dari 60-80\% pemakaian air bersih (PERMEN PUPR NO 4, 2017). Tabel 3. menjelaskan bahwa total kebutuhan air bersih di Mal X sebesar 104,66 m³/hari dengan jumlah dari pemakaian air oleh karyawan sebesar 24,90 $\mathrm{m}^{3}$ / hari; tenan sebesar $45,60 \mathrm{~m}^{3} /$ hari dan pengunjung sebesar 34,16 $\mathrm{m}^{3} /$ hari. Sehingga timbulan air limbah yang dihasilkan adalah $80 \%$ dari kebutuhan air bersih yaitu $83,73 \mathrm{~m}^{3} /$ hari.

\subsection{Karakteristik Air Limbah}

Sumber air limbah mal seluruhnya berasal dari kegiatan operasional mal yaitu food court, toilet, pembersihan dan pemeliharaan. Khusus air limbah yang berasal dari food court mengandung residu makanan, sabun pembersih, minyak dan lemak tinggi. Senyawa organik yang terkandung dalam air limbah food court berupa karbohidrat, protein, lemak dan minyak. Kandungan dalam air limbah tersebut berasal dari kegiatan operasional dapur mulai dari proses mempersiapkan bahan makanan meliputi pemilahan dan pencucian bahan baku, proses pengolahan makanan, proses pembersihan peralatan memasak dan peralatan makan, air buangan sisa makanan dan sisa makanan seperti nasi, sayuran, minyak dan lemak

Tabel 7. Pertimbangan pemilihan alternatif

\begin{tabular}{|c|c|c|c|}
\hline Parameter & Lumpur Aktif & Trickling filter & $\mathrm{RBC}$ \\
\hline $\begin{array}{l}\text { Kemudahan } \\
\text { Pengopera- } \\
\text { sian }\end{array}$ & $\begin{array}{l}\text { Suplai oksigen menggunakan } \\
\text { aerator sehingga membutuhkan } \\
\text { energi yang lebih besar, perlu } \\
\text { pengontrolan } \\
\text { Mood/ } \\
\text { kriteria desain agar mencegah } \\
\text { terjadinya bulking (pertumbuhan } \\
\text { tidak normal yang mengakibatkan } \\
\text { lumpur aktif berubah menjadi } \\
\text { keputih-putihan). Pengontrolan } \\
\text { mudah dilakukan karena jenis } \\
\text { mikroorganisme yang digunakan } \\
\text { tidak bervariasi (Said, 2017). }\end{array}$ & $\begin{array}{l}\text { Suplai oksigen dapat diperoleh secara } \\
\text { alami dari permukaan atas namun } \\
\text { suplai oksigen ini tidak merata } \\
\text { sampai ke bagian bawah sehingga } \\
\text { terjadi kondisi anaerob yang } \\
\text { menimbulkan bau, tidak bisa diisi } \\
\text { dengan beban organik yang tinggi } \\
\text { karena biofilm akan bertambah } \\
\text { sehingga dapat menimbulkan } \\
\text { (clogging) penyumbatan pada filter } \\
\text { (Said, 2017) }\end{array}$ & $\begin{array}{l}\text { Suplai oksigen dapat diperoleh } \\
\text { secara alami dari proses putaran } \\
\text { disk. Pengontrolan jumlah } \\
\text { mikroorganismenya sulit karena } \\
\text { mikroorganisme bervariasi, menim- } \\
\text { bulkan pertumbuhan cacing air } \\
\text { sehingga di dalam reaktornya } \\
\text { terdapat gumpalan merah yang } \\
\text { melayang, sering terjadi } \\
\text { penyumbatan (clogging) pada media } \\
\text { (Said, 2017). }\end{array}$ \\
\hline $\begin{array}{l}\text { Jumlah } \\
\text { akumulasi } \\
\text { lumpur }\end{array}$ & $\begin{array}{l}\text { Lumpur yang dihasilkan banyak } \\
\text { karena hampir } 30-60 \% \text { senyawa } \\
\text { organik yang disisihkan diubah } \\
\text { menjadi lumpur (Said, 2017). }\end{array}$ & $\begin{array}{l}\text { Lumpur yang dihasilkan lebih } \\
\text { sedikit, hanya 10-30\% dari senyawa } \\
\text { organik karena pada biofilm rantai } \\
\text { makanan lebih panjang dan } \\
\text { melibatkan aktivitas mikroorganisme } \\
\text { dengan orde yang lebih tinggi (Said, } \\
\text { 2017). }\end{array}$ & $\begin{array}{l}\text { Lumpur yang dihasilkan lebih } \\
\text { sedikit, hanya 10-30\% dari senyawa } \\
\text { organik karena pada biofilm rantai } \\
\text { makanan lebih panjang dan } \\
\text { melibatkan aktivitas mikroorganisme } \\
\text { dengan orde yang lebih tinggi (Said, } \\
\text { 2017). }\end{array}$ \\
\hline $\begin{array}{l}\text { Kualitas } \\
\text { efluen }\end{array}$ & $\begin{array}{l}\text { Efisiensi pengolahan } 85-95 \% \\
\text { (Qasim, 1985). }\end{array}$ & $\begin{array}{l}\text { Efisiensi pengolahan } \\
\text { (Qasim, 1985). }\end{array}$ & $\begin{array}{l}\text { Efisiensi pengolahan } 80-85 \% \\
\text { (Qasim, 1985). }\end{array}$ \\
\hline $\begin{array}{l}\text { Kebutuhan } \\
\text { lahan }\end{array}$ & $\begin{array}{l}\text { Tidak memerlukan lahan yang luas } \\
\text { namun tergantung dari debit air } \\
\text { limbah yang akan diolah (Said, } \\
\text { 2017). }\end{array}$ & $\begin{array}{l}\text { Tidak memerlukan lahan yang luas } \\
\text { namun tergantung dari debit air } \\
\text { limbah yang akan diolah (Said, } \\
\text { 2017). }\end{array}$ & $\begin{array}{l}\text { Tidak memerlukan lahan yang luas } \\
\text { namun tergantung dari debit air } \\
\text { limbah yang akan diolah (Said, } \\
\text { 2017). }\end{array}$ \\
\hline $\begin{array}{l}\text { Biaya } \\
\text { pengopera- } \\
\text { sian }\end{array}$ & $\begin{array}{l}\text { Konstruksi awal tidak memerlukan } \\
\text { biaya tinggi, namun konsumsi } \\
\text { energi tinggi karena membutuhkan } \\
\text { suplai oksigen sehingga biaya } \\
\text { yang dibutuhkan tinggi (Said, } \\
\text { 2017). }\end{array}$ & $\begin{array}{l}\text { Konstruksi awal dan media } \\
\text { membutuhkan biaya tinggi. } \\
\text { Pengoperasiannya membutuhkan } \\
\text { energi untuk memutar distributor } \\
\text { (Said, 2017). }\end{array}$ & $\begin{array}{l}\text { Konstruksi awal tidak memerlukan } \\
\text { biaya tinggi namun membutuhkan } \\
\text { biaya untuk media disk. Konsumsi } \\
\text { energi lebih rendah untuk } \\
\text { pengolahan kapasitas kecil (Said, } \\
\text { 2017). }\end{array}$ \\
\hline
\end{tabular}




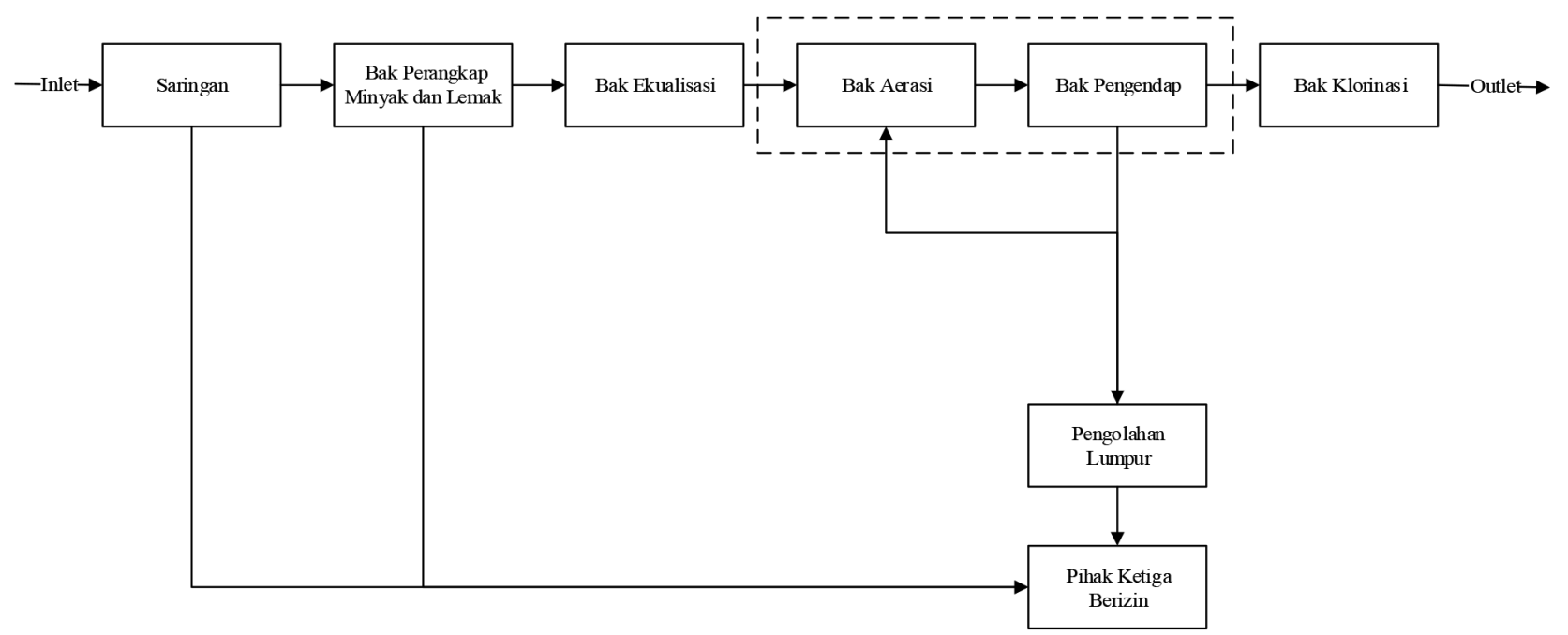

Gambar 2. Rangkaian unit pengolahan air limbah terpilih

(Zahra dan Purwanti, 2015).

Bahan makanan seperti sayur dan buah-buahan menghasilkan air limbah yang mengandung partikel padatan dan zat organik terlarut, sedangkan daging olahan dan hasil laut mengandung polutan organik tinggi berasal dari darah dan isi perut (Said, 2017).

Jenis makanan yang bermacam-macam dari food court akan menghasilkan air limbah yang mempunyai jumlah dan jenis bahan organik dalam jumlah besar, dalam hal ini akan mempersulit pengelolaan karena beberapa zat sulit diuraikan oleh mikroorganisme. Langkah untuk menentukan besarnya kandungan bahan organik menggunakan beberapa teknik pengujian seperti BOD dan COD. Uji BOD merupakan parameter yang sering digunakan untuk mengetahui tingkat pencemaran bahan organik, baik dari industri ataupun dari rumah tangga (Setiyono dan Rahayu, 2017).

Karakteristik air limbah dianalisis pada saat hari kerja dan hari libur waktu pagi hari. Sampel air limbah diambil pada satu titik yaitu pipa inlet bak kontrol sebelum masuk ke dalam tangki septik. Hasil pengukuran sampel air limbah Mal X dapat dilihat pada Tabel 4.

Berdasarkan hasil pengukuran sampel air limbah Mal X pada Tabel 4 menunjukkan bahwa hampir seluruh parameter pencemar memenuhi baku mutu Peraturan Menteri Lingkungan Hidup dan Kehutanan No. 68 Tahun 2016 tentang baku mutu air limbah domestik, hanya parameter TSS pada hari libur yang melebihi baku mutu yaitu sebesar $35 \mathrm{mg} / \mathrm{l}$ sedangkan baku mutu menunjukan konsentrasi maksimum TSS yang diperbolehkan sebesar $30 \mathrm{mg} / \mathrm{l}$. Hal ini disebabkan pengunjung mal pada saat hari libur akan lebih banyak dibandingkan hari kerja sehingga konsentrasi pencemar akan lebih tinggi. Pengukuran sampel air limbah yang dilakukan hanya bersumber dari kegiatan saat ini di mana tenan yang baru beroperasi hanya 14 tenan dari total keseluruhan tenan 304 tenan.

Hasil pengukuran tersebut belum bisa merepresentatifkan seluruh kegiatan yang akan berjalan karena semakin banyak tenan yang beroperasi maka konsentrasi pencemar pun akan semakin tinggi, sehingga diperlukan adanya perkiraan karakteristik air limbah dari beberapa sumber penelitian sejenis. Terdapat tiga penelitian sejenis yang melakukan pengukuran kualitas air limbah di pusat perbelanjaan. Parameter pencemar utama dalam pengukuran kualitas air limbah tersebut adalah parameter BOD, COD, TSS, minyak dan lemak.

Hasil penelitian tersebut dapat dilihat pada Tabel 5. Berdasarkan Tabel 5 dari tiga penelitian sejenis maka dihitung rata-rata untuk memperoleh konsentrasi air limbah sehingga diperoleh hasil konsentrasi BOD, COD, TSS dan minyak dan lemak berurut-turut sebesar 182,67 mg/l; 328,50 mg/l; 255,92 mg/l; $47,93 \mathrm{mg} / \mathrm{l}$. Rasio BOD/COD 0,56. Karakteristik air limbah yang akan digunakan diambil rata-rata karena dianggap air limbah dari kegiatan yang sejenis memiliki karakteristik yang sama.

\subsection{Efisiensi Pengolahan}

Efisiensi pengolahan marupakan target yang harus dipenuhi unit pengolah agar efluen tidak mencemari badan air penerima. Efisiensi pengolahan dihitung dengan mengurangi nilai konsentrasi yang masuk dengan baku mutu dibagi dengan konsentrasi yang masuk (Tchobanoglous dkk., 2004). Efisiensi minimum yang perlu dicapai unit pengolahan dapat dilihat pada Tabel 6. Berdasarkan Tabel 6 efisiensi terbesar diperlukan untuk menyisihkan parameter 
minyak dan lemak yaitu mencapai $90 \%$.

\subsection{Alternatif Pengolahan}

\subsubsection{Inventarisasi dan Alternatif Pengolahan}

Teknologi pengolahan air limbah mal terdiri dari pengolahan pendahuluan, sekunder, dan tertier. Perencanaan IPAL Mal X disusun sebanyak tiga alternatif. Pengolahan primer dan pengolahan tersier dalam rangkaian unit pengolahannya dibuat sama dengan pertimbangan menurut Tchobanoglous dkk. (2004) untuk air limbah dengan rasio BOD/COD $\geq$ 0,5 maka pengolahan yang tepat adalah pengolahan biologi sesuai dengan rasio BOD/COD yang diperoleh yaitu sebesar 0,56 .

Rasio BOD/COD merupakan suatu indikator dampak dari zat organik yang berada dalam air limbah untuk menentukan proses pengolahan agar efluen yang dihasilkan aman untuk dibuang ke badan air. Parameter BOD dan COD tersebut merupakan parameter utama dalam penentuan zat organik. Air limbah domestik lebih mudah terdegradasi secara biologis dari pada air limbah industri. Ketika tingkat degradasi air limbah semakin tinggi maka rasio BOD/COD berbanding lurus menjadi semakin besar. Rasio BOD/COD terbagi menjadi dua klasifikasi (a) zona biodegradable dengan nilai $\mathrm{BOD} / \mathrm{COD} \geq 0,5$ pengolahannya menggunakan proses biologis (b) zona toksik dengan nilai $\mathrm{BOD} / \mathrm{COD} \leq 0,3$ pengolahannya kurang cocok menggunakan proses biologis karena memerlukan proses penyesuaian cukup lama agar mikroorganisme dapat beradaptasi dengan air limbah (Samudro dan Mangkoediharjo, 2010).

Pengolahan pendahuluan berupa saringan (screening) dipilih untuk memisahkan antara limbah padat yang mungkin ikut masuk bersama air limbah yaitu berupa pembalut dan tisu dari toilet, potongan sayuran berukuran besar, tulang-tulang atau sisa-sisa makanan dari food court. Material-material ini perlu disisihkan sejak dari awal karena dikhawatirkan apabila ikut masuk dapat merusak unit operasi selanjutnya atau merusak pompa (Qasim, 1985).

Selanjutnya air limbah dialirkan ke bangunan perangkap minyak dan lemak. Bak perangkap minyak dan lemak adalah sebuah unit yang didesain untuk menyisihkan minyak dan lemak yang terakumulasi di permukaan air. Minyak dan lemak dalam air akan menyebabkan berkurangnya tingkat degradasi air oleh mikroorganisme dan mengganggu pemeliharaan unit pengolahan selanjutnya. Air limbah dari bak perangkap minyak dan lemak akan dialirkan ke bak ekuilisasi. Bak ekualisasi berfungsi untuk menyeragamkan konsentrasi dan debit sehingga tidak menimbulkan masalah shock loading di unit pengolahan sekunder.
Shock loading akan mempengaruhi kinerja mikroorganisme sehingga efisiensi pengolahan tidak optimal (Tchobanoglous dkk., 2004).

Pengolahan sekunder yaitu pengolahan dengan proses biologis difokuskan untuk menyisihkan senyawa organik yang terdapat di dalam air limbah. Penyisihan senyawa organik dibantu oleh aktivitas mikroorganisme. Pengolahan biologi berdasarkan jenis mikroorganisme terbagi menjadi dua klasifikasi yaitu aerobik dan anaerobik. Pengolahan dengan jenis anaerobik digunakan untuk mengolah air limbah yang pekat biasanya air limbah yang berasal dari industri sehingga untuk pengolahan air limbah di mal $X$ digunakan pengolahan aerobik (Tchobanoglous dkk., 2004) .

Selain itu pengolahan air limbah secara biologis berdasarkan jenis biakkan dibagi menjadi tiga klasifikasi yaitu dengan biakan tersuspensi (suspended growth system), biakan melekat (attached growth system) dan proses pengolahan dengan sistem kolam (lagoon). Proses pengolahan biologi dengan sistem kolam harus memiliki lahan yang cukup besar sehingga sistem tersebut tidak terpilih. Proses biologis dengan biakan tersuspensi merupakan sistem pengolahan menggunakan aktivitas mikroorganisme dalam penguraian senyawa polutan organik yang ada di dalam air limbah. Mikroorganisme yang digunakannya pun dibiakkan secara tersuspensi dalam suatu reaktor. Beberapa contoh teknologi pengolahan air limbah dengan sistem ini adalah lumpur aktif (activated sludge), step aeration, contact stabilization, extended aeration dan oxidation ditch. Pengolahan dengan step aeration, contact stabilization, extended aeration dan oxidation ditch membutuhkan lahan yang besar dan pengoperasian yang rumit sehingga unit pengolahan yang dipilih adalah lumpur aktif. Istilah lumpur aktif diambil dari fakta bahwa endapan lumpur yang diendapkan di dalam bak pengendapan akhir mengandung mikoorganisme yang masih hidup dan disirkulasikan kembali ke dalam reaktor (aeration tank) digunakan untuk meningkatkan jumlah biomassa dan untuk mempercepat reaksi (Said, 2017).

Proses biologis dengan biakkan melekatmerupakan pengolahan air limbah di mana mikroorganisme yang digunakan berkembangbiak pada suatu media sehinga melekat pada permukaan media tersebut. Proses ini disebut juga dengan proses film mikrobiologis/proses biofilm. Beberapa contoh dari pengolahan air limbah dengan sistem ini adalah trickling filter, reaktor kontak biologis putar (Rotating Biological Contactor/ $\mathrm{RBC}$ ). Pengolahan dengan trickling filter merupakan dilakukan dengan cara menyebarkan air limbah ke dalam suatu tumpukan media yang terdiri dari bahan 
batu pecah (kerikil), bahan keramik, sisa tanur (slag), medium dari bahan plastik dan lainya. Selanjutnya akan tumbuh lapisan biologis (biofilm) seperti lendir di permukaan media lalu mengalami kontak dengan air limbah sehingga parameter pencemar pada air limbah dapat diuraikan (Said, 2017).

$\mathrm{RBC}$ adalah adaptasi dari proses pengolahan air limbah dengan biakan melekat (attached growth). Media yang digunakan berupa piring tipis (disk) bentuk bulat dipasang berjajar dalam suatu poros yang terbuat dari baja. Disk tersebut selanjutnya diputar di dalam suatu reaktor yang di dalamnya dialirkan air limbah secara kontinu (Tchobanoglous dkk., 2004). Kedua unit tersebut dipilih untuk menjadi pilihan dalam alternatif pengolahan air limbah mal X karena memenuhi kriteria pertimbangan pemilihan yaitu tidak memerlukan lahan yang luas dan kemudahan pengoperasian (Said, 2017).

Unit pengolahan yang direncanakan dipilih dari tiga alternatif. Alternatif pertama yaitu menggunakan lumpur aktif, kedua menggunakan trickling filter dan ketiga menggunakan RBC. Air limbah dari unit pengolahan tersebut akan dialirkan menuju bak pengendap. Bak pengendap ini berfungsi untuk menyisihkan flok/lumpur biologis hasil proses pengolahan biologi (Tchobanoglous dkk., 2004).

Pengolahan tertier merupakan proses untuk menghasilkan air olahan dengan kualitas yang lebih baik. Unit pengolahan yang dipilih adalah bak klorinasi. Bak klorinasi ini berfungsi untuk memusnahkan mikroorganisme yang dapat menimbulkan penyakit dengan menambahkan klor (Said, 2017).

Rangkaian alternatif pengolahan IPAL pertama terdiri dari saringan, bak perangkap minyak dan lemak, bak ekualisasi, lumpur aktif, bak pengendap dan bak klorinasi. Alternatif kedua dan ketiga memiliki rangkaian unit pengolahan yang sama dengan rangkaian unit pengolahan yang pertama namun berbeda pada unit pengolahan biologinya. Alternatif kedua menggunakan trickling filter dan alternatif ketiga menggunakan RBC.

Pemilihan alternatif pengolahan berdasarkan parameter-parameter pertimbahan pengolahan air limbah. Irman (2015) menyatakan bahwa parameter pemilihan alternatif pengolahan air limbah berdasarkan (a) kemudahan pengoperasian menjadi bahan pertimbangan karena berpengaruh terhadap sumber daya manusia yang ahli, operasional dan pemeliharaan unit pengolahan (b) jumlah akumulasi lumpur yang dihasilkan akan mempengaruhi biaya operasi semakin banyak lumpur yang dihasilkan semakin banyak pula biaya yang harus dikeluarkan (c) kualitas efluen yang dihasilkan harus sesuai dengan baku mutu yang berlaku semakin ketat nilai ambang batasnya maka efisiensi pengolahan air limbah semakin tinggi (d) kebutuhan lahan apabila luas unit pengolahan besar maka semakin besar luas lahan yang diperlukan (e) biaya pengoperasian ditentukan berdasarkan kebutuhan energi, bahan kimia dan perawatan unit pengolahan. Adapun dua parameter penting yang perlu dipertimbangkan dalam pemilihan alternatif pengolahan di mal $\mathrm{X}$ yaitu parameter kemudahan pengoperasian dan kebutuhan lahan. Pertimbangan dalam pemilihan alternatif dapat dilihat pada Tabel 7.

Tabel 7 menjelaskan bahwa untuk parameter kemudahan pengoperasian alternatif satu (lumpur aktif) lebih unggul dibandingkan akternatif lainnya. Selanjutnya untuk parameter jumlah akumulasi alternatif dua (trickling filter) dan alternatif tiga (RBC) sama unggul dibandingkan alternatif satu. Kualitas efluen yang dihasilkan dari alternatif satu lebih unggul dibandingkan alternatif lainnya. Parameter kebutuhan lahan, lahan yang dibutuhkan untuk ketiga alternatif sama unggul.

Parameter terakhir yaitu biaya pengoperasian alternatif satu dan alternatif tiga lebih unggul dibandingkan alternatif dua. Hasil analisis tersebut menunjukkan bahwa alternatif satu lebih unggul dibandingkan alternatif lainnya berdasarkan parameter pemilihan pengolahan air limbah sehingga alternatif satu adalah alternatif terpilih. Sehingga rangkaian unit pengolahan air limbah untuk mal X adalah saringan, bak perangkap minyak dan lemak, bak ekualisasi, lumpur aktif, bak pengendap dan bak klorinasi. Rangkaian unit tersebut dapat dilihat pada Gambar 2. Pengolahan dalam lumpur aktif tentunnya akan menghasilkan lumpur yang selanjutnya dialirkan menuju bak pengendap. Lumpur yang diendapkan dalam bak pengendap mengandung mikroorganisme yang masih hidup. Lumpur yang mengandung mikroorganisme masih hidup akan disirkulasikan kembali menuju tangki aerasi sedangkan sisa lumpur lainnya akan diolah di pengolahan lumpur. Lumpur yang dihasilkan dari pengolahan biologi ini diolah kembali di pengolahan lumpur yang diserahkan kepada pihak ketiga berizin. Begitu pula dengan limbah padat dari unit saringan, minyak dan lemak dari bak perangkap minyak dan lemak akan diserahkan kepada pihak ketiga berizin.

\subsection{Dimensi Unit Pengolahan}

Perhitungan dimensi unit IPAL di Mal X berdasarkan kriteria desain yang diperoleh dari berbagai literatur, debit air limbah yang masuk sebesar $83,73 \mathrm{~m}^{3} /$ hari dengan konsentrasi dari karakteristik air limbah untuk parameter BOD, COD, TSS dan minyak 
dan lemak berurut-turut sebesar 182,67 mg/l; 328,50 $\mathrm{mg} / 1 ; 255,92 \mathrm{mg} / 1 ; 47,93 \mathrm{mg} / 1$.

1. Saringan yang akan digunakan berupa plat yang penuh lubang. Disimpan sebelum air limbah masuk ke bak perangkap minyak. Bak perangkap minyak, kriteria desain bak perangkap minyak sebagai berikut (Said, 2017):

Waktu detensi $\left(\mathrm{t}_{\mathrm{d}}\right)=30-60$ menit (Direktorat Bina Pelayanan Penunjang Medik dan Sarana Kesehatan, 2011) Efisiensi pengolahan $=95 \%$ (Wongthanate dkk., 2014)

Kedalaman bak $(\mathrm{h})=1 \mathrm{~m}$, freeboard $=0,3 \mathrm{~m}$, dan rasio $\mathrm{P}: \mathrm{L}=2: 1$ (Qasim, 1985)

Persamaan untuk menghitung dimensi bak perangkap minyak yaitu:

a. Volume bak perangkap minyak (V)

$$
\mathrm{V}=\mathrm{Q} \times \mathrm{t}_{\mathrm{d}}
$$

b. Luas permukaan bak (A)

$\mathrm{A}=\mathrm{V} / \mathrm{h}$

c. Dimensi bak perangkap minyak $\mathrm{L}=(\mathrm{A} / 2)^{0,5}$ dan $\mathrm{P}=2 \mathrm{~L}$

d. Cek waktu detensi $\left(\mathrm{t}_{\mathrm{d}}\right)$ $\mathrm{t}_{\mathrm{d}}=$ Vaktual/Q

e. Konsentrasi minyak dan lemak yang tersisa $\left(\mathrm{C}_{\text {out }}\right)$ $\mathrm{C}_{\text {out }}=(100-95) / 100 \times \mathrm{C}_{\text {in }}$

Bak Ekualisasi, kriteria desain bak ekualisasi sebagai berikut (Said, 2017):

- Waktu detensi (HRT) = 8 jam,

- Kedalaman bak $(\mathrm{h})=2 \mathrm{~m}$, freeboard $=0,3 \mathrm{~m}$, dan Rasio P:L = 2:1

Persamaan untuk menghitung dimensi bak ekuilisasi yaitu:

a. Volume bak pengendap (V) $\mathrm{V}=\mathrm{Q} \times \mathrm{HRT}$

b. Luas permukaan bak (A) $\mathrm{A}=\mathrm{V} / \mathrm{h}$

c. Dimensi bak perangkap minyak, $\mathrm{L}=(\mathrm{A} / 2)^{0,5}$ dan $\mathrm{P}=2 \mathrm{~L}$

d. Cek waktu detensi (HRT) HRT = Vaktual/Q

Lumpur aktif kriteria desain lumpur aktif sebagai berikut (Said, 2017):

- Mixed Liquor Suspended Solid (MLSS) = $1.500-2.000 \mathrm{mg} / 1$

- Rasio Food/Microorganism (Rasio F/M) =0,2 $\mathrm{kg} \mathrm{BOD} / \mathrm{kg}$ MLSS.hari

- Rasio sirkulasi lumpur $(\mathrm{R})=0,25$

- Return sludge $\left(\mathrm{C}_{\mathrm{R}}\right)=8.000 \mathrm{mg} / \mathrm{l}$

- Kedalaman bak $(\mathrm{h})=3 \mathrm{~m}$, freeboard $=0,3 \mathrm{~m}$, dan rasio $P: L=2: 1$

- Jumlah oksigen yang dikonsumsi per jumlah BOD yang dihilangkan $\left(a^{\prime}\right)=0,42$
- Oksigen yang dikonsumsi oleh respirasi endogenous ( $\left.\mathrm{b}^{\prime}\right)=0,12$

- Berat oksigen per $\mathrm{m}^{3}$ udara $=0,285 \mathrm{~kg}$

- Volume oksigen terlarut $=5 \%$

Said (2017) menyatakan bahwa MLSS, rasio F/M, rasio sirkulasi lumpur merupakan variabel perencanaan dalam lumpur aktif. MLSS adalah campuran dari air limbah dengan biomassa mikroorganisme dan padatan tersuspensi lainnya. Rasio F/M menunjukkan jumlah zat organik (BOD) yang disisihkan dibagi dengan jumlah massa mikroorganisme di dalam bak aerasi. Pengaturan laju sirkulasi lumpur aktif dari bak pengendapan akhir yang disirkulasikan ke bak aerasi dapat mengontrol rasio F/M. Rasio sirkulasi lumpur merupakan perbandingan banyaknya lumpur yang disirkulasikan ke bak aerasi dengan banyaknya air limbah yang masuk ke dalam bak aerasi.

Perencanaan dalam perhitungan lumpur aktif menggunakan data konsentrasi dari karakteristik air limbah yang telah diperoleh dan baku mutu yang digunakan seperti:

$\operatorname{BODin}\left(\mathrm{S}_{\mathrm{o}}\right)=182,67 \mathrm{mg} / \mathrm{l}$

BODout $(\mathrm{S})=30 \mathrm{mg} / 1$

$\operatorname{TSSin}\left(\mathrm{SS}_{\mathrm{in}}\right)=255,92 \mathrm{mg} / \mathrm{l}$

TSSout $\left(_{\text {sSout) }}=30 \mathrm{mg} / 1\right.$ (PERMEN LHK No 68 Tahun 2016)

Persamaan untuk menghitung dimensi bak aerasi lumpur aktif yaitu:

a. Jumlah MLSS

MLSS $=\frac{\left(C_{s s} \text { in }- \text { Css out }\right)+R \times C_{R}}{1+R}$

b. Volume lumpur aktif (V) $\mathrm{V}=\frac{\mathrm{Q} \times \mathrm{SSO}_{\mathrm{O}}}{\mathrm{MLSS} \times \mathrm{Rasio} \mathrm{F} / \mathrm{M}}$

c. Luas permukaan lumpur aktif (A)

$\mathrm{A}=\mathrm{V} / \mathrm{h}$

d. Dimensi lumpur aktif $\mathrm{L}=(\mathrm{A} / 2)^{0,5}$ dan $\mathrm{P}=2 \mathrm{~L}$

e. Cek waktu detensi (HRT) HRT $=$ Vaktual/Q

f. Beban BOD dalam lumpur aktif

- Beban $\mathrm{BOD}_{\text {in }}=\mathrm{Q} \times \mathrm{S}_{\text {。 }}$

- Jumlah BOD $_{\text {out }}=\mathrm{Q} \times \stackrel{\circ}{\mathrm{S}}$

g. Jumlah BOD yang hilang $\left(\mathrm{BOD}_{\mathrm{R}}\right)$ $\mathrm{BOD}_{\mathrm{R}}=\left(\mathrm{BOD}_{\text {in }}-\mathrm{BOD}_{\text {out }}\right)$

h. Jumlah kebutuhan oksigen $\left(\mathrm{R}_{\mathrm{o}}\right)$ $\mathrm{R}_{\mathrm{o}}=\mathrm{a}^{\prime} \times \mathrm{BOD}_{\mathrm{R}}+\mathrm{b}^{\prime} \mathrm{x} \mathrm{X}$ $\mathrm{X}=\operatorname{MLSS} \mathrm{x} \mathrm{Q}$

i. Volume udara yang dibutuhkan (V) $\mathrm{V}=\frac{\mathrm{Ro}}{\text { Berat oksigen x oksigen terlarut }}$

Bak Pengendap, kriteria desain bak pengendap sebagai berikut (Said, 2017):

- Waktu detensi (HRT) = 2-4 jam

- Beban permukaan (surface loading rate/SLR) = $25-30 \mathrm{~m}^{3} / \mathrm{m}^{2}$.hari 
- Kedalaman $=3 \mathrm{~m}$ dan freeboard $=0,3 \mathrm{~m}$ dan Rasio P:L $=2: 1$

Said (2017) menyatakan bahwa beban permukaan merupakan parameter utama dalam bak pengendap. Beban permukaan digunakan untuk menghitung pembatasan pemekatan dari bak pengendap akhir. Desain bak sering dikontrol oleh SLR yang diizinkan, di mana berhubungan dengan sifat pemekatan lumpur.

Persamaan untuk menghitung dimensi bak pengendap lumpur aktif yaitu:
a. Volume bak pengendap (V)$$
\mathrm{V}=\mathrm{Q} \times \mathrm{HRT}
$$
b. Luas permukaan bak (A) $\mathrm{A}=\mathrm{V} / \mathrm{h}$
c. Dimensi bak pengendap $\mathrm{L}=(\mathrm{A} / 2)^{0,5}$ dan $\mathrm{P}=2 \mathrm{~L}$
d. Cek waktu detensi (HRT) HRT $=$ Vaktual/Q
e. Cek SLR

$$
\mathrm{SLR}=\mathrm{Q} / \mathrm{A}
$$

Bak Klorinasi, kriteria desain bak klorinasi sebagai berikut (Fair dkk., 1968):

- Konsentrasi klor dalam kaporit $\mathrm{Ca}(\mathrm{OCl})_{2}=70 \%$ Daya pengikat klor (DPC) selama 30 menit untuk air limbah = 2,5 mg/l (Komariyah dan Sugito, 2011)

Sisa klor yang diharapkan $=0,5 \mathrm{mg} / 1$

Waktu detensi $\left(\mathrm{t}_{\mathrm{d}}\right)=30-120$ menit

Kedalaman $(\mathrm{h})=1 \mathrm{~m}$, freeboard $=0,3 \mathrm{~m}$, dan rasio $\mathrm{P}: \mathrm{L}=2: 1$

Persamaan yang dipergunakan untuk menghitung dimensi bak klorinasi yaitu:
a. Kebutuhan klor
Klor $=$ DPC + Sisa klor
b. Kebutuhan kaporit
Kaporit $=\mathrm{Q} \times \%$ Klor dalam kaporit $\mathrm{x}$ Kebutuhan klor
c. Volume bak klorinasi (V)

$$
\mathrm{V}=\mathrm{Q} \times \mathrm{t}_{\mathrm{d}}
$$
d. Luas permukaan bak (A)

$$
A=V / h
$$
e. Dimensi bak klorinasi

$$
\mathrm{L}=(\mathrm{A} / 2)^{0,5} \text { dan } \mathrm{P}=2 \mathrm{~L}
$$

Hasil perhitungan dimensi untuk setiap unit pengolahan dapat dilihat pada Tabel 8. Unit-unit pengolahan yang dihitung dimensinya antara lain unit bak perangkap minyak dan lemak, bak ekualisasi, lumpur aktif, bak pengendap dan bak klorinasi. Unit saringan dalam perencanaan di beli dengan kriteria saringan berupa plat yang penuh lubang. Total kebutuhan lahan yang diperkirakan dari hasil perhitungan dimensi unit pengolahan untuk membangun IPAL Mal X sekitar $80 \mathrm{~m}^{2}$.
Tabel 8. Dimensi unit pengolahan

\begin{tabular}{lccc}
\hline \multicolumn{1}{c}{ Unit Pengolahan } & $\begin{array}{c}\text { Panjang } \\
(\mathrm{m})\end{array}$ & $\begin{array}{c}\text { Lebar } \\
(\mathrm{m})\end{array}$ & $\begin{array}{c}\text { Tinggi } \\
(\mathrm{m})\end{array}$ \\
\hline Bak perangkap minyak dan & 3,0 & 1,5 & 1,0 \\
lemak & 5,5 & 3,0 & 2,0 \\
Bak ekualisasi & 5,0 & 2,5 & 3,0 \\
Lumpur aktif & 3,0 & 1,5 & 3,0 \\
Bak pengendap & 3,0 & 1,5 & 1,0 \\
Bak klorinasi & & & \\
\hline
\end{tabular}

\section{Kesimpulan}

Mal X mengalami perubahan konsep dari mal yang menjual alat elektronik menjadi food court. Hal tersebut menyebabkan terjadinya perubahan jumlah dan karakteristik air limbah yang dihasilkan. Kondisi saat ini pengolahan air limbah dilakukan dengan menggunakan tangki septik tanpa bidang resapan yang terletak di basement mal tersebut. Perubahan jumlah dan karakteristik limbah yang dihasilkan memerlukan perencanaan IPAL yang sesuai. Berdasarkan hasil penelitian diperoleh kesimpulan bahwa rangkaian unit IPAL terpilih yaitu saringan, bak perangkap minyak dan lemak, bak ekualisasi, lumpur aktif, bak pengendap dan bak klorinasi.

Berdasarkan hasil perhitungan diperlukan luas lahan kurang lebih sekitar $80 \mathrm{~m}^{2}$ untuk membangun keseluruhan unit IPAL tersebut yang mampu mengolah air limbah sebesar $83,73 \mathrm{~m}^{3} /$ hari. Lumpur yang dihasilkan dari proses pengolahan akan diserahkan kepada pihak ketiga yang sudah memiliki izin.

\section{Daftar Pustaka}

Anonim 2017. Deskripsi Kegiatan Click Square Mal Bandung, Bandung, PT Bumi Artha Gemilang.

Chen, C. K. \& LO, S. L. 2006. Treating Restaurant Using A Combined Activated Sludge Contact Aeration System. Journal of Environmental Biology.

Direktorat Bina Pelayanan Penunjang Medik Dan Sarana Kesehatan 2011.

Fair, G. M., Geyer, J. C. \& Okun, D. A. 1968. Water and Wastewater Treatment Engineering, New York, John Wiley \& Sons Inc.

Hamid, A. \& Razif, M. 2014. Perbandingan Desain IPAL Proses Attach Growth Anaerobic Filter dengan Suspended Growth Anaerobic Baffled Reactor untuk Pusat Pertokoan di Kota Surabaya. Journal Teknik Pormits, 3 .

Irman. 2015. Sistem Pengolahan Air Limbah Secara Biologis [Online]. Available: https://www. slideshare.net/metrosanita/sistem-pengolahanair-limbah-secara-biologis [Accessed].

Komariyah, S. \& Sugito 2011. Perencanaan IPAL Biofilter di UPTD Kesehatan Puskesmas 
Gondang Wetan Kabupaten Pasuruan. Jurnal Teknik, 9.

Lukito, E. 2017. Perancangan Ulang Instalasi Pengolahan Air Limbah (IPAL) Pusat Perbelanjaan "X" Surabaya. Departemen Teknik Lingkungan Fakultas Tekik Sipil dan Perencanaan Institut Teknologi Sepuluh November.

Permen LHK No.68 Tahun 2016 Baku Mutu Air Limbah Domestik, Indonesia.

Permen PUPR No. 4 tahun 2017. Perencanaan SPALD, Indonesia.

Qasim, S. R. 1985. Wastewater Treatment Plants Planning, Design and Operation, New York, CBS Collage Publishing.

Said, N. I. 2017. Teknologi Pengolahan Air Limbah Teori dan Aplikasi, Penerbit Erlangga.

Samudro, G. \& Mangkoediharjo, S. 2010. Review on BOD, COD and BOD/COD Ratio: A Triangle Zone For Toxic, Biodegradable and Stable Levels. International Journal of Academic Research.

Setiyono \& Rahayu 2017. Teknologi Pengolahan Limbah Cair Rumah Makan.

SNI 03-7065-2005 Tata Cara Perencanaan Sistem Plambing, Indonesia, Badan Standarisasi Nasional.

SNI 6989-59-2008 2008. Metoda Pengambilan Contoh Air Limbah, Indonesia, Badan Standarisasi Nasional.

Sugiyono 2017. Metode Penelitian Kuantitatif, Kualitatif dan $R \& D$, Bandung, Alfabeta.

Tchobanoglous, G., Burton, F. L. \& Stensel, H. D. 2004. Wastewater Engineering Treatment and Reuse, New York, Mc Graw Hill.

Wongthanate, J., Mapracha, N., Prapagdee, B. \& Arunlertaree, C. 2014. Efficiency of Modified Grease Trap for Domestic Wastewater Treatment. The Journal of Industrial technology, 10.

Zahra, L. Z. \& Purwanti, I. F. 2015. Pengolahan Limbah Rumah Makan dengan Proses Biofilter Aerobik. Teknik ITS, 4. 